\title{
Characteristics of Asthma-COPD Overlap According to Various Criteria
}

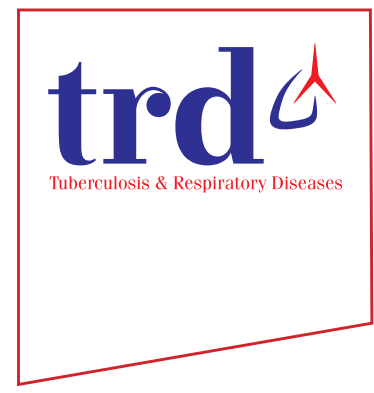

\author{
Ji Ye Jung, M.D. (1)
}

Division of Pulmonology, Department of Internal Medicine, Severance Hospital, Yonsei University College of Medicine, Seoul, Republic of Korea

Asthma and chronic obstructive pulmonary disease (COPD) have been traditionally considered distinct clinical entities, but they are frequently diagnosed as respiratory ailments. About $15 \%-20 \%$ of patients with either asthma or COPD manifest overlapping features.

Asthma and COPD overlap (ACO) is an umbrella term of multiple subphenotypes that include patients who have predominant asthma with some COPD features and others with predominant COPD with some asthma features ${ }^{1,2}$. Most studies on ACO have demonstrated a higher overall burden of exacerbations or healthcare utilization than that with either asthma or COPD alone $\mathrm{e}^{3,4}$.

The prevalence of ACO has been reported to be up to onethird of asthma patients and one-quarter of COPD patients ${ }^{5}$. This wide range is due to the various definitions used to identify ACO. Sin et al. ${ }^{6}$ proposed a case definition of ACO that may help clinicians to diagnose patients with ACO more accurately and researchers to design therapeutic and clinical studies. However, various diagnostic algorithms have been reported in different countries, indicating that no single universally accepted definition of ACO has emerged ${ }^{7-9}$.

Lim et al. ${ }^{10}$ compared clinical presentations and the appropriateness of four different sets of criteria for diagnosing ACO in a cohort of Korean COPD patients. Those authors also investigated which criteria are most applicable to a Korean ACO

\footnotetext{
Address for correspondence: Ji Ye Jung, M.D.

Division of Pulmonology, Department of Internal Medicine, Severance Hospital, Yonsei University College of Medicine, 50-1 Yonsei-ro, Seodaemun-gu, Seoul 03722, Republic of Korea

Phone: 82-2-2228-1931, Fax: 82-2-2228-2273

E-mail: stopyes@yuhs.ac

Received: Dec. 3, 2020

Revised: Dec. 5, 2020

Accepted: Dec. 7, 2020

Published online: Dec. 7, 2020

(c) It is identical to the Creative Commons Attribution Non-Commercial License (http://creativecommons.org/licenses/by-nc/4.0/).
}

population ${ }^{10}$. Four different sets of criteria include the American Thoracic Society (ATS) roundtable criteria, the modified Spanish Society of Pneumonology and Thoracic Surgery (SEPAR) criteria, the Global Initiative for Asthma (GINA)/Global Initiative for Chronic Obstructive Lung Disease (GOLD) criteria, and specialists' diagnoses ${ }^{6,11,12}$. The prevalence of ACO was $24.4 \%$ according to specialists' diagnoses, followed by $16.0 \%$, $13.6 \%$, and $2.2 \%$ according to the GINA/GOLD, SEPAR, and ATS Roundtable criteria. The clinical characteristics between ACO and non-ACO patients vary according to the different sets of criteria. However, a greater decline in forced expiratory volume in 1 second $\left(\mathrm{FEV}_{1}\right)$ was observed during 3 years of follow-up in an ACO group than in a non-ACO group according to the SEPAR criteria and specialists' diagnoses; this was also nearly the case according to the ATS Roundtable criteria $(\mathrm{p}=0.093)$. If more patients in the ACO group were compared with those in the non-ACO group, a significant decline in $\mathrm{FEV}_{1}$ would have been observed. Moreover, the decline in forced vital capacity (FVC) was also more significant in the ACO group than in the non-ACO group according to the ATS Roundtable criteria and the specialists' diagnosis, although a small number of patients were categorized in the ACO group according to the ATS Roundtable criteria.

However, Park et al. ${ }^{13}$ reported that patients with ACO exhibit a slower annual decline in $\mathrm{FEV}_{1}$ than COPD patients without ACO over a median follow-up of 5.8 years. A change in lung function over the follow-up period would depend on baseline lung function because low baseline lung function may result in a smaller change. Lim et al. ${ }^{10}$ showed a higher $\mathrm{FEV}_{1}$ and FVC in an ACO group than a non-ACO group, which may result in a larger decline over 3 years. Moreover, the authors' used mean delta values between baseline and year 3 to evaluate the changes in $\mathrm{FEV}_{1}$ and FVC. This statistical method resulted in only a small number of patients included in the analysis. If those authors had conducted a linear mixed analysis, more patients would have been included. In addition, a description of the proportion of ACO patients who met all four or fewer criteria would help to assess the diagnostic scope of each criterion. Despite several limitations of the study, the authors found disparities in the clinical presentation and longitudinal outcomes in the different criteria of the ACO definitions. 
They also reported that the ATS Roundtable criteria may not be appropriate for clinical use in Korea and that clinical diagnosis by specialists is more comprehensive and practical ${ }^{10}$.

The ATS Roundtable and SEPAR criteria include blood eosinophil count but not fractional exhaled nitric oxide (FeNO). There is no well-established FeNO cutoff value that defines an "asthmatic" phenotype among smokers with an airflow limitation. Some studies have suggested a cutoff value of 35 parts per billion (ppb), while others have recommended a $50 \mathrm{ppb}$ threshold ${ }^{12,14}$. Few studies have investigated the role and utility of FeNO in Korean COPD patients ${ }^{15,16}$. Ahn et al. ${ }^{16}$ reported various FeNO levels in COPD patients. Asthma history, blood eosinophil percentage $>3 \%$, and a positive bronchodilator response were independent risk factors for FeNO level ${ }^{16}$. Jo et al. ${ }^{15}$ reported that increased FeNO is associated with a history of asthma regardless of wheezing. However, in real-world clinics, FeNO seems to play a subsidiary role in the use of inhaled corticosteroids-containing inhalers ${ }^{15}$.

ACO is not a single entity or a syndrome, but a collection of clinical features. Recognizing patients with features of both diseases is important to guide clinical care. Although a universally accepted consensus on its definition and diagnostic and clinical features are required, it may not be uniformly defined for different ethnicities.

\section{Conflicts of Interest}

No potential conflict of interest relevant to this article was reported.

\section{References}

1. Postma DS, Rabe KF. The asthma-COPD overlap syndrome. N Engl J Med 2015;373:1241-9.

2. Boulet LP, Hanania NA. The many faces of asthma-chronic obstructive pulmonary disease overlap. Curr Opin Pulm Med 2019;25:1-10.

3. Ekerljung L, Mincheva R, Hagstad S, Bjerg A, Telg G, Stratelis G, et al. Prevalence, clinical characteristics and morbidity of the asthma-COPD overlap in a general population sample. J Asthma 2018;55:461-9.

4. Zeki AA, Jarjour NN. The asthma-chronic obstructive pulmonary disease overlap syndrome: a new take on an old concept. Ann Am Thorac Soc 2016;13:1440-2.

5. Alshabanat A, Zafari Z, Albanyan O, Dairi M, FitzGerald JM.
Asthma and COPD overlap syndrome (ACOS): a systematic review and meta analysis. PLoS One 2015;10:e0136065.

6. Sin DD, Miravitlles M, Mannino DM, Soriano JB, Price D, Celli $\mathrm{BR}$, et al. What is asthma-COPD overlap syndrome? Towards a consensus definition from a round table discussion. Eur Respir J 2016;48:664-73.

7. Miravitlles M, Alvarez-Gutierrez FJ, Calle M, Casanova C, Cosio BG, Lopez-Vina A, et al. Algorithm for identification of asthma-COPD overlap: consensus between the Spanish COPD and asthma guidelines. Eur Respir J 2017;49:1700068.

8. Cosio BG, Soriano JB, Lopez-Campos JL, Calle-Rubio M, Soler-Cataluna JJ, de-Torres JP, et al. Defining the asthma-COPD overlap syndrome in a COPD cohort. Chest 2016;149:45-52.

9. Cataldo D, Corhay JL, Derom E, Louis R, Marchand E, Michils A, et al. A Belgian survey on the diagnosis of asthma-COPD overlap syndrome. Int J Chron Obstruct Pulmon Dis 2017;12: 601-13.

10. Lim JU, Kim DK, Lee MG, Hwang YI, Shin KC, In KH, et al. Clinical characteristics and changes of clinical features in patients with asthma-COPD overlap in Korea according to different diagnostic criteria. Tuberc Respir Dis 2020;83(Suppl 1):S34-45.

11. Soler-Cataluna JJ, Cosio B, Izquierdo JL, Lopez-Campos JL, Marin JM, Aguero R, et al. Consensus document on the overlap phenotype COPD-asthma in COPD. Arch Bronconeumol 2012;48:331-7.

12. Global Initiative for Asthma, Global Initiative for Chronic Obstructive Lung Disease. A Joint Project of GINA and GOLD. Diagnosis and initial treatment of asthma, COPD and asthma-COPD overlap. Fontana: Global Initiative for Asthma; 2019.

13. Park HY, Lee SY, Kang D, Cho J, Lee H, Lim SY, et al. Favorable longitudinal change of lung function in patients with asthmaCOPD overlap from a COPD cohort. Respir Res 2018;19:36.

14. Tamada T, Sugiura H, Takahashi T, Matsunaga K, Kimura K, Katsumata U, et al. Biomarker-based detection of asthmaCOPD overlap syndrome in COPD populations. Int J Chron Obstruct Pulmon Dis 2015;10:2169-76.

15. Jo YS, Choe J, Shin SH, Koo HK, Lee WY, Kim YI, et al. Exhaled nitric oxide in patients with stable chronic obstructive pulmonary disease: clinical implications of the use of inhaled corticosteroids. Tuberc Respir Dis 2020;83:42-50.

16. Ahn S, Kim TO, Chang J, Shin HJ, Kwon YS, Lim SC, et al. Clinical features of chronic obstructive pulmonary disease with high fractional exhaled nitric oxide. Tuberc Respir Dis 2020;83:234-41. 